\title{
MARKETING INFORMATION SYSTEM
}

\section{PAVEL BRUNDA}

Silesian University in Opava

School of Business Administration in Karviná

Department of Communication

Czech Republic

Tel.: + 420696398276

Fax: + 420696312069

e-mail: brunda@opf.slu.cz

Key Words:

executive information system, strategic marketing, process architecture, IT integration

This article is supposed to take a look at the Marketing Information System (MIS) as an analytical tool for marketing managers and specialists who seek to find an instrument for systematisation of information, automation of routine processes and facilitation of decision-making processes. These functions should be integrated into the main company system and should benefit from the information and data stored elsewhere in/outside the company. First of all, we would like to present the different information types which a marketer usually attempts to collect.

\section{MARKETING INFORMATION [1]}

\begin{abstract}
Analysis of competition
First of all the system should integrate and provide with information systematically collected on the competitors of all kinds, i.e. a) the existing, direct competitors, b) once the marketer identifies potential competition this is also to be added, c) the substitute producers, d) suppliers and finally e) customers. All the categories of competitors have to be continuously analysed and inserted in the datawarehouse. Such items as concentration of competitors, differentiation and range of products, intensity of competition or the customer's willingness to change brands will be the core of this function.
\end{abstract}

Based on the analysis of processed information the system should facilitate the process of setting the competition strategy: a) Porter's strategy (i)the lowest costs, ii) differentiation, iii) niche product), or b) Kotler's strategy (i) leader, ii) challenger, iii) follower, iv) niche operator).

\section{Macroeconomic environment}

Besides the information about the forces in the market the marketer has to have at his/her disposal information on the factors which he may not influence. This category names information ranging from a) demographic trends (e.g. number or age of inhabitants), b) socio-economic trends (connected to culture, un/employment, and leisure time), c) ecological 
trends, d) technological factors (fast progress in production) up to e) political factors (restructuring programs, taxation). Although these qualitative information items are less convenient for entry into the system, it may include legislation norms, information resources and secondary resources of information.

\section{Market analysis}

The market may be characterised and analysed in the following ways: a) market in units (e.g. money, visitors), b) effective demand, i.e. a total number of really sold products, c) potential demand, that is number of items which might be sold. The system should be able to count the market volumes in different ways and units as well as provide with the figures on penetration (also cumulative) and market share.

\section{Customer's behaviour}

The decisive factor in this category is whether we operate at a consumer or industrial market. When operating on the industrial market we will tend to specify in which stage of purchase the customer is at the given point (specification of the problem, product, searching for suppliers and so on). We will classify three stages of purchase: a) initial (original market), b) alternative, modified or c) direct repeated, routine. A nother decision is whether to produce or purchase, the manager will specify possibilities of external supply, risk rate, quality requirements and others. The individual customer will be classified and described according to the following criteria [3]: a) culture and subculture (divided according to e.g. age, religion), b) social status (based for instance on occupation, education), c) social impacts (family, life cycle), d) individual factors (income, personality), and e) psychological factors, such as physiological needs, social security and so on. Additionally, it is important to identify the purchase role, for instance initiator, decision-maker, customer or user.

\section{Distribution analysis}

Information gathered in this section concerns the alternative distribution channels, analysis of customer's preferences and a sort of the product (everyday, luxurious). Distribution, similarly to other company activities, has to be revised regularly in order to ensure a continuous improvement.

\section{Marketing strategy}

Finally the manager will need information on the company activities compared in different times, compared to competition, plan and marketing strategy. This information will be provided based on a) analysis of the sales, b) analysis of the market share, the whole market or a sector where the company operates, c) analysis of the sales, costs and profit, d) analysis of the marketing policy, e) analysis of the target group, f) analysis of the marketing mix (policy of product, prices, distribution, marketing communication) and last but not least g) analysis of marketing activities.

\section{Financial analysis}

Although this is not primary information for the marketer, general overview is necessary for him/her to take strategic decisions and evaluate the operation of the company and its marketing/sales activities. Out of the indicators based on the balance sheet the following can be named: a) indicators of company's liquidity - i) current ratio, ii) quick ratio and iii) working capital - b) indicators of solvency - i) capital ratio and ii) registered capital to total assets ratio - c) indicators of profitability - i) profitability, ii) total capital profitability, iii) profitability of equity - d) indicators of company's activity - i) sales coefficient, ii) sales profitability, iii) return on capital. 
Besides the above-mentioned analyses the system should serve as a supportive tool in making more strategic decisions based on intuition and professional background of the manager. The following categories should provide with basic alternative solutions for the manager who would finally make the special decisions.

\section{Product policy}

The product is the most important part of the marketing mix. First the product has to be identified - we distinguish between the physical, extended and total product. This function should facilitate definition of assortment policy - which products to add, remove -, policy of a group of products and policy of product attributes. Regarding the assortment we will focus on the length and depth. Concerning the product attributes, we speak about the policy of mark, which represents quality for the customer.

Quite an important feature of the product is the product cycle and marketing policy. It is relevant for the marketer to have at his/her disposal continuous information on the stage in which the product at the point of time is. All the marketing activities, i.e. product strategy, price strategy, commercial strategy and so on, vary in the stages of introduction, growth, stagnation, saturation and fall. M oreover, for the marketer it is priceless information to know retrospectively the development of the sales in comparison with the activities, tools and remedies applied.

\section{Price policy}

At the occasion of introduction of a new product, changes at the market and other situations the marketer needs to deal with price fixing. He needs to have at his disposal the demand curve and to know the demand elasticity. Also, the analysis of the break-even point is convenient. Out of the basic information it is possible to determine the price strategy, that is strategy in terms of a) price policy, b) price and assortment, c) price variability, d) new price for new products, e) competition, f) maintaining the price. The system should offer a range of methods for price fixing. A mong them belong a) methods oriented at costs (e.g. based on the break-even point), b) methods oriented at the demand and customer (based on research, analyses), c) methods oriented at competition (e.g. imitation).

\section{Distribution policy}

This category is aimed at fixing a distribution channel based for instance on the characteristics of the customer, product, competition and so on. Then the distribution targets should be determined - intensive, selective or exclusive distribution. Finally, the distribution costs, numerical distribution and indicators like market share will be calculated.

\section{Sales and commercial policy}

This information will include communication marketing mix, commercials and their impacts, direct marketing, promotion policy and the targets of promotion. The commercial policy will be based on information on the target group, setting aims, selection of the commercial strategy, setting the message, selection of the media, budget and evaluation of the effect.

\section{INFORAMTION SYSTEM [2]}

\section{MIS in the organisational hierarchy of the company}

The overall system information is build up from construction blocks which are characterised by a) their factual orientation (purchase, accounting) and b) management level (operative, tactical, strategic). 
Strategic

Tactical

Operative

\begin{tabular}{|c|c|c|}
\hline \multirow{3}{*}{ EDI } & EIS (e.g. MIS) & \multirow{2}{*}{ OIS } \\
\cline { 2 - 3 } & TIS & \\
\cline { 2 - 3 } & TPS & \\
\hline
\end{tabular}

TPS - Transaction Processing System is the bloc focused on the main activity of the company. It is the most specified system and depends on the character of the company (production, trading). The systems are based on integration of two principles - production (development, design) and orders (accepting, planning material requirements). They are based on CIM (Computer Integrated $M$ anufacturing) concepts, consisting for instance of CAD (design), CAM (manufacturing).

TIS - Tactical level Management Information System. This level includes commercial and logistic applications: above all purchase, sales, supplying, warehousing, transport. Financial applications include controlling, wages, work and financial control.

EIS - Executive Information System is oriented at strategic management of the company. The top management applications are designed to gain information from the other application of the company system (TPS, TIS). They aggregate such data and create time sequences and mutual relationships. The systems enable to view different information at different points of time, for instance to see a sales plan in this year $R$, year $R-1$ and year $R+1$. Thus, the quality of managerial decisions may be evaluated. The systems work with an a-dimensional worksheet, the first dimension is the given indicator, the second dimension is time and the third dimension is the selected point of view, e.g. territory [4]. This level of information system includes al so M arketing Information System (MIS).

OIS - Office Information System is a bloc devised for the support of office and team work. The following applications may serve as examples: word processor, worksheet, presentation or e-mail program.

EDI - Electronic Data Interchange ensures communication of the company with its environment, i.e. banks, institutions, suppliers and so on.

\section{Partial IS/IT Architectures}

In a choice of MIS the marketer will be interested in the special functions and the network of their relationships. Therefore, it is necessary to briefly consider the individual aspects of the system, i.e. partial architectures.

\section{Functional architecture}

This structure reflects the processes taking place in the company with the support of IS. This view is static and divides the individual functions into the smallest items - elementary functions (transactions). The higher levels would be then sets of immediately subordinate functions. This structure is critical because it enables definition of all the functions and processes in the company which may be described and automated. Then we define the events - information, extraordinary action or time - which trigger the elementary functions.

\section{Process architecture}

It is a proposal of the future processes in the company. It suggests networks of non-automated activities and functions in IS which are planned reactions to certain data, time or extraordinary events. The goal is the fastest response possible to the external events. It is necessary to clearly state the external activities and relationship of the company with the surrounding. An instrument for description of processes is the context diagram which is based on the detailed scheme of elementary functions - Data Flow Diagram (DFD). 


\section{Data architecture}

It shows the structure and physical placement of the data, defines the data types - signal, structural, genetic.

\section{Software, hardware and technological architecture}

These architectures identify what software and hardware components will be used, where they will be located, what their structures will be and so on. As this article concentrates on the special marketing functions of the systems, these aspects are merely mentioned in brief.

A s it may be apparent from the paragraphs above the role of a marketer will rather rest in the definition of the process and functional architectures. The other structures should be designed and maintained by IS/IT specialists.

\section{Criteria for the selection of a relevant system}

Choosing the information system for a company is a complex system which demands a team co-operation of different specialists. Commonly such an order would take a form of a tender where there would be more potential suppliers in question. Therefore, the highest attention has to be paid to selection of relevant criteria. A gain, in this paper we will focus on the part of a marketing specialist who would be able to define the parameters and processes/functions which an ideal system would provide.

In terms of marketing the following criteria are to be considered/met:

a) summarisation of the offer - expected effects of the solution, guarantee of the offered functions

b) overall concept - fulfilling of company goals, flexibility of the system, required organisational changes

c) specification of the application software - individual functional units, tasks, degree of coverage of the individual functions, data, hierarchy of functions, the relationships, possible modifications, respecting legislation

d) services - economic and organisational consulting (esp. Business Process R eengineering), training, hot-line

e) guarantee - application software, integrity of the whole system, complaints

f) transfer from the existing to new IS - functional (incremental start of the individual functions), data, organisation (e.g. new department, new functions), personnel

g) schedule of the solution - final term, individual stages

h) price specification - what is included

i) references

\section{Trends in the Czech Republic}

In the Czech Republic after the V elvet Revolution we could observe a boom of companies processing data. In the 90 's the market had the following structure: a) several tens of bigger companies oriented on complex supplies Some of them operate only as system integrators and do not offer the whole range of service, b) several hundreds of companies orientated on special ised information services, such as: consulting, smaller projects, supply of a specialised product, supply of a specialised service (company LAN), training. 
Table 1: Sales of the biggest IT companies in CR

\begin{tabular}{|c|l|c|c|c|}
\hline \multirow{2}{*}{ Order } & \multicolumn{1}{|c|}{ Company } & \multicolumn{2}{|c|}{ Sales in CZK mil } & Growth 94/95 in \\
\cline { 3 - 4 } & & $\mathbf{1 9 9 4}$ & $\mathbf{1 9 9 5}$ & \\
\hline 1. & IBM CR & 2,600 & 3,570 & 37 \\
\hline 2. & Hewlett-Packard CR & 2,380 & 3,500 & 47 \\
\hline 3. & PVT & 2,263 & 2,483 & 10 \\
\hline 4. & Elko Computers & 1,848 & 3,105 & 68 \\
\hline 5. & Th' System & 1,640 & 1,905 & 16 \\
\hline 6. & Digital Equipment & 1,215 & 1,690 & 39 \\
\hline 7. & Vikomt & 1,190 & 890 & -25 \\
\hline 8. & A utocont & 1,080 & 1,800 & 67 \\
\hline 9. & Escom CS & 966 & 876 & -9 \\
\hline 10. & Siemens Nixdorf IS & 925 & 665 & -28 \\
\hline
\end{tabular}

Source: magazine Computer World (25/95, 50/95, 17/96)

It is apparent that the most important companies are world operators. However, among the five most successful companies belong five corporation which were originally sellers of PCs and adequate software. The exception is PVT company which started as a supplier of IT for RM -system, Czech al ternative stock exchange.

The following table shows the order of companies supplying application software.

Table 2: Companies supplying application software

\begin{tabular}{|c|l|c|c|}
\hline \multirow{2}{*}{ Order } & \multicolumn{1}{|c|}{ Company } & \multicolumn{2}{|c|}{ Sales in CZK mil } \\
\cline { 3 - 4 } & & $\mathbf{1 9 9 4}$ & $\mathbf{1 9 9 5}$ \\
\hline 1. & IB M CR & 2,600 & 3,570 \\
\hline 2. & PVT & 2,263 & 2,783 \\
\hline 3. & Digital Equipment & 1,215 & 1,690 \\
\hline 4. & Siemens Nixdorf IS & 925 & 665 \\
\hline 5. & APP Systems & 650 & 670 \\
\hline 6. & SAP CR & 414 & 554 \\
\hline 7. & HT Computer & 400 & 500 \\
\hline 8. & OR Computer Systems & 280 & 295 \\
\hline 9. & A pro & 252 & 242 \\
\hline 10. & PragoData & 220 & 217 \\
\hline
\end{tabular}

Source: magazine Computer World (25/95, 50/95, 17/96)

It is al so worth saying that in the Czech R epublic the investments into IT are the highest in the Central Europe (dada from year 1995), i.e. USD 115 per capita, compared to Slovakia USD 108, Poland USD 21 or Russia USD 18.

In conclusion, I would like to point out that this paper suggest only some aspects of the $M$ arketing Information System and is a part of a wider study of M IS in the Czech companies, whose goal is to analyse the system from the marketing point of view and suggest functions which it should offer to make the marketer's work easier, based on factual information which comes in time. A part of the study is analysis of the present products at the market, above all examining the process/functional architectures. This is however dependent to a large extent on willingness of the companies to provide with such information. 


\section{References:}

[1] K otler, P.: M arketing M anagement. Prentice H all. 1991. ISBN 80-85605-0802

[2] Vorisek, ].: Strategic M anagement of IT and System Integration. Management Press. Prague 1999. ISBN 80-85943-40-9

[3] Mezulánik, J.: How to A pproach Complaints in Banking Business Communication after Year 2000. In: FUTURE OF THE BANK ING AFTER THE YEAR 2000 IN THE WORLD AND IN THE CZECH REPUBLIC. ISBN: 80-7248-017-0, OPF SU K arviná 1998.

[4] Nenadal, J.: M odern Systems of Quality M anagement. M anagement Press. Prague 1999. ISBN 80-85943-63-8 